Journal homepage: http://www.journalijar.com

Journal DOI: $\underline{10.21474 / I J A R 01}$

RESEARCH ARTICLE
INTERNATIONAL JOURNAL

OF ADVANCED RESEARCH

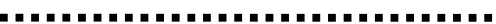

ISSN NO. 2320-5407

\title{
RECENT DEVELOPMENTS IN ENAMEL AND DENTINE REMINERALISATION: AN UPDATE.
}

\author{
Dr. Rajeev Pandey ${ }^{1}$, Dr Anit Khatri ${ }^{2}$, Dr. Rajat Gupta ${ }^{1}$, Dr. Nitin Bhagat ${ }^{1}$.
}

1. School of Dental Sciences, Sharda University, Greater Noida, Uttar Pradesh , India.

2. Private Practitioner, Kalol (N.G.), Gujarat, India.

\section{Manuscript Info}

Manuscript History:

Received: 19 March 2016

Final Accepted: 19 April 2016

Published Online: May 2016

Key words:

Remineralisation, Bioactive glass,

Ozone, CPP-ACP,

Demineralisation, Xylitol,

Enamelon

*Corresponding Author

Dr. Rajeev Pandey.

\section{Abstract}

Field of dentistry has grown in leaps and bounds in the last decade. Now the focus has shifted from operative to preventive dentistry. Research in caries has shifted from traditional surgical approach to early intervention and prevention of caries for early carious lesions. This has been possible due to advent of various remineralising agents. These agents control the demineralisation/remineralisation cycle around the tooth. This article highlights the various newer agents and discusses their application.

\section{Introduction:-}

Dental caries is the most common dental problem. According to Shafer it is an irreversible microbial disease of calcified tissues of the teeth, characterized by demineralisation of the inorganic portion and destruction of the organic substance of the tooth, which often leads to cavitation. Tooth inside oral cavity is under battle of demineralisation and remineralisation. This battle is under the control of the $\mathrm{pH}$ status of the oral cavity. Increase in $\mathrm{pH}$ leads to remineralizing process and vice versa ${ }^{7}$. Equilibrium $\mathrm{pH}$ can be disturbed by environmental factors like plaque leading to dental caries due to demineralisation. Demineralisation occurs due to loss of calcium, phosphate and other minerals leading to dissolution of subsurface enamel crystals. This process is reversible if the environment around the tooth is changed leading to increase in $\mathrm{pH}$ leading to remineralisation. Various agents had been tried and developed which can help in remineralisation. This article discuss the newly developed agents and their application in caries prevention through remineralisation .Some of the ideal agents are bioactive glass, ozone, CPP-ACP, xylitol, Enamelon.

\section{Recent dentin and enamel remineralising agents:-}

\section{Bioactive Glass:-}

These are surface active glasses composed of oxides of calcium, sodium, silicon and phosphorus ${ }^{2,3}$. These agents are biocompatible, and form a bone like apatite layer on its surface along with regeneration of bone. Their application in dentistry is based on dentin mineralization and remineralisation. In saliva calcium phosphosilicate particles release sodium ions which begin to exchange with hydrogen which in turn allows release of calcium and phosphate. This helps in transient increase in $\mathrm{pH}$ leading to precipitation of calcium and phosphate and formation of calcium phosphate on tooth surface. Calcium phosphate deposition continues which crystallizes into hydroxyl carbonate apatite. This property of bioactive glass can be utilized for remineralisation techniques because the crystalline hydroxyl carbonate apetite is chemically and structurally similar to hydroxyapetite in natural teeth. 


\section{Ozone:-}

Ozone is derived from Greek word "ozein". It is a gas allotrope discovered by Christian Friedrich Schönbeinin in 1840. Ozone can kill bacteria in carious lesions, help in oxidizing organic material within the carious dentin, helps in opening of channels inside dentin leading to penetration of calcium and phosphate ions and remineralisation.

In vitro studies have shown that ozone helps in remineralisation of dentin ${ }^{14}$.

Ozone is a toxic gas especially for pulmonary tract. Therefore for its use in medicine one must avoid its toxicity with the help of special instruments like precise ozone generator equipped with well-standardised photometer, appropriate monitor, ozone destructor and an emergency air depurator.

CPP-ACP (Casein phosphor peptides-amorphous calcium phosphate):

These are nano complexes comprised of bovine milk, casein, calcium and phosphate.

Various in vitro, animal as well as human studies has proven its remineralizing and anticariogenic properties ${ }^{10,11,12}$. It was Prof. Eric Reyolds who first postulated its remineralizing properties ${ }^{9}$. Mechanism of action of CPP is based upon its ability to bind and stabilize calcium and phosphate and helps in binding it to enamel by keeping them in an amorphous non crystalline state. This will help in remineralisation and reduce demineralisation.

Synergetic effect of CPP along with fluoride has been observed in animal and well as human studies ${ }^{8,13}$. It is attributed to the formation of ACFP (amorphous calcium fluoride phosphate).

When CPP-ACP was incorporated with glass ionomer cement (GIC) there was increase in micro tensile bond strength, compressive strength of GIC and enhanced release of calcium, phosphate, and fluoride ions at neutral and acidic $\mathrm{pH}$. An in vitro study by Mazzaoui et al has shown that $1.56 \%$ CPP-ACP containing GIC is a superior restorative material with improved anti cariogenic properties ${ }^{4}$.

Various application of CPP-ACP includes- use as tooth mousse for children under 2 year of age, use in patients with special needs and those with intellectual impairment, developmental and physical disabilities, cerebral palsy, Down syndrome, high caries risk patients, white spot lesion, erosion of teeth, prevention of tooth wear, dentinal hypersensitivity, and as a substitute to commercial tooth pastes.

\section{Xylitol:-}

Xylitol is a polyol sugar alcohol derived from plums, strawberries, rowan berries and raspberries. Term xylitol is derived from "xylose" meaning wood sugar. Many studies have shown its anticariogenic and remineralisation properties $^{1}$. The proposed mechanism of action includes, it is not fermented by bacteria, helps to increase in the concentration of amino acids and ammonia, thereby neutralizing plaque acids, bacteriostatic action, changes the quality and quantity of saliva, specific action on enamel for remineralisation.

It also has specific actions on mutans streptococci, main culprit for initiation of dental caries including its bacteriostactic action and effect on metabolic cycle.

Xylitol is available in various forms or part of various preparations which includes chewing gum, candy lozenge, tooth pastes, chewable medication, cough drops, vitamins, breath mints, calcium supplements, antacids. Few problems associated with use of xylitol includes: diarrhoea, stomach cramping, and flatulence. Also it is an expensive sugar substitute.

\section{Enamelon:-}

Enamelon comprises of phosphate salts and sodium fluoride separated from unstabilized calcium in a toothpaste tube by a plastic divider. The demineralising and anticariogenic property of Enamelon is based on fact that it is a form of liquid calcium which delievers fluoride along with soluble calcium and phosphate. It helps in reduction of root surface caries. It also helps in desensitization of cervical dentine ${ }^{5,6}$. Only technical issue with Enamelon is formation of insoluble precipitates of calcium and phosphate before they come into contact with saliva or enamel. 


\section{Conclusion:-}

Dental caries is a dynamic process balanced upon $\mathrm{pH}$. The goal in dental practice is to help the patient to maintain an oral environment that prevents demineralisation and enhances remineralisation to prevent the formation of dental caries. Development and application of these agents can prevent and reverse dental caries.

\section{References:-}

1. Alanen, P., Isokangas, P., Gutmann, K., (2000). Xylitol candies in caries prevention: results of a field study in Estonian children. Comm Dent Oral Epidemiol. 28(3):218-24.

2. Gatti, A., Valdre, G., Andersson, O. (1994). Analysis of the in vivo reactions of a bioactive glass in soft and hard tissue. Biomaterials. 15:208-12.

3. Heikkila, J.T., Aho, H.J., Yli-Urpo, A., Andersson, O.H., Aho, A.J., Happonen, R.P. (1993). Bioactive glass is as good as hydroxylapatite in reconstruction of experimental osteochondral defects. Acta Orthop Scand. 64:672-78.

4. Mazzaoui, S.A., Burrow, M.F., Tyas, M.J., Dashper, S.G., Eakins, D., Reynolds, E.C., (2003). Incorporation of casein phosphopeptide-amorphous calcium phosphate into glass-ionomer cement. J Dent Res. 82(11):914-8.

5. Papas, A., Russell, D., Singh, M., Kent, R., Triol, C., Winston, A., (2008). Caries clinical trial of a remineralising toothpaste in radiation patients. Gerodontology. 25(2):76-88.

6. Papas, A., Russell, D., Singh, M., Stack, K., Kent, R., Triol, C., Winston, A., (1999). Double blind clinical trial of a remineralizing dentifrice in the prevention of caries in a radiation therapy population. Gerodontology. 16(1):2-10.

7. Rao, A., Malhotra, N. (2011). The role of remineralizing agents in dentistry: A review. Compend Contin Educ Dent. 32(6):26-33.

8. Reynolds, E.C., Cain, C.J., Webber, F.L., Black, C.L., Riley, P.F., et al. (1995). Anticariogenicity of calcium phosphate complexes of tryptic casein phosphopeptides in the rat. J Dent Res. 74(6):1272-9.

9. Reynolds, E.C., (1998). Anticariogenic complexes of amorphous calcium phosphate stabilized by casein phosphopeptides: A review. Spec Care Dentist. 18(1):8-16.

10. Reynolds, E.C., et al. (1999). Advances in enamel remineralisation: Anticariogenic casein phosphopeptideamorphous calcium phosphate. J Clin Dent. 10:86-8.

11. Reynolds, E.C., et al. (2003). Retention in plaque and remineralisation of enamel lesion by various forms of calcium in a mouthrinse or sugar-free chewing gum. J Dent Res. 82:206-11.

12. Shen, F., et al. (2001). Remineralisation of enamel subsurface lesions by sugar-free chewing gum containing casein phosphopeptide-amorphous calcium phosphate. J Dent Res. 80:2066-70.

13. Walsh, L.J., (2000). Preventive dentistry for the general dental practitioner. Aust Dent J. 45(2):76-82.

14. Zaura, E., Buijs, M.J., Cate, J.M. (2007). Effects of ozone and sodium hypochlorite on caries-like lesions in dentin. Caries Res. 41(6):489-92. 